\title{
Avaliação de Métodos Alternativos a Citologia no Rastreamento de Lesões Cervicais: Detecção de DNA-HPV e Inspeção Visual
}

\author{
Evaluation of Alternative Methods in Cervical Screening: HPV-DNA \\ Detection and Visual Inspection
}

\begin{abstract}
Renata Gontijo, Sophie Françoise M. Derchain, Cecília Roteli-Martins, Luis Otávio Zanatta Sarain, Joana Fróes Bragança, Samara Messias da Silva, Luiz Carlos Zeferino
\end{abstract}

Objetivo: avaliar o desempenho da citologia oncológica (CO), captura híbrida II (CH II) para detecção de DNA-HPV e inspeção visual com ácido acético a 5\% (IVA) na detecção de lesões cervicais.

Métodos: foram avaliadas 2281 mulheres submetidas à coleta de material para $\mathrm{CO}, \mathrm{CH}$ II e a IVA. As mulheres com pelo menos um exame positivo eram convocadas para colposcopia, que também foi realizada em 420 mulheres com todos os exames normais. O desempenho dos testes foi calculado tendo como padrão-ouro a colposcopia com ou sem biopsia.

Resultados: a CO foi anormal em 209 (9,2\%) mulheres, a CH II foi positiva em 399 (17,5\%) e em 249 (10,9\%) foram encontradas alterações à IVA. Entre as 2281 mulheres avaliadas, 671 (29,4\%) apresentaram pelo menos um resultado de exame positivo embora apenas 82 (3,6\%) apresentassem doença histológica (50 NIC1, 20 NIC2, sete NIC3 e cinco carcinomas invasores). A sensibilidade da IVA e da CH II foram semelhantes $e$ significativamente maiores que a da CO. A especificidade da CO foi maior que a da IVA e da CH II. Nos casos com resultado de CO negativo, a IVA apresentou melhor desempenho comparada à $\mathrm{CH}$ II.

Conclusão: a detecção de lesão histológica foi baixa. O desempenho da CO com a IVA foi melhor que o da CO com a CH II e do que o da CO isolada.

PALAVRAS-CHAVE: Rastreamento. Colo do útero: lesões pré-neoplásicas. Colo do útero: carcinoma. Citologia. Captura de híbridas. 